\title{
Multi-point monitoring of nitrous oxide emissions and aeration efficiency in a full-scale conventional activated sludge tank
}
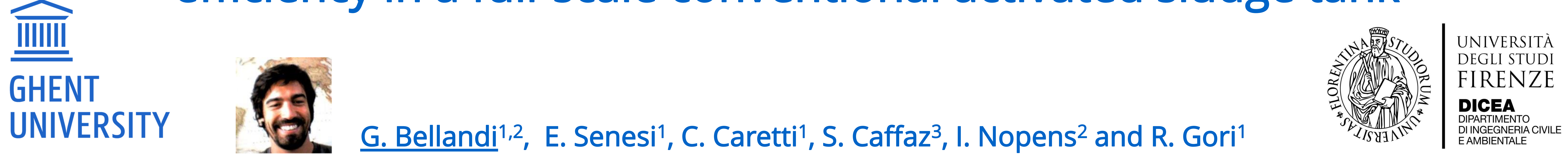

1 Department of Civil and Environmental Engineering, University of Florence, via di S. Marta 3, 50139 Florence, Italy

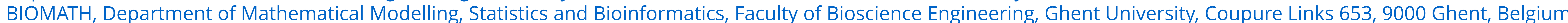
${ }^{3}$ Publiacqua SpA, Via Romania snc, 50055 Lastra a Signa, Florence, Italy

\section{Introduction}

$\mathrm{N}_{2} \mathrm{O}$ is a potent greenhouse gas (GHG) that can be produced during biological N removal. In WRRFs using activated sludge (AS) technology it can represent by itself $78 \%$ of the plant carbon footprint (CFP). However, emissions have high spatial and temporal variability (due to mixing problems and influent dynamics).

Aeration efficiency can account for up to $50 \%$ of the plant CFP. Assessment of aeration performances needs careful planning and the generally accepted $2 \%$ coverage not always

A proper spatial and temporal coverage of the tank is needed for a reliable assessment of emissions and aerators performances.

\section{$\mathrm{N}_{2} \mathrm{O}$ emissions}
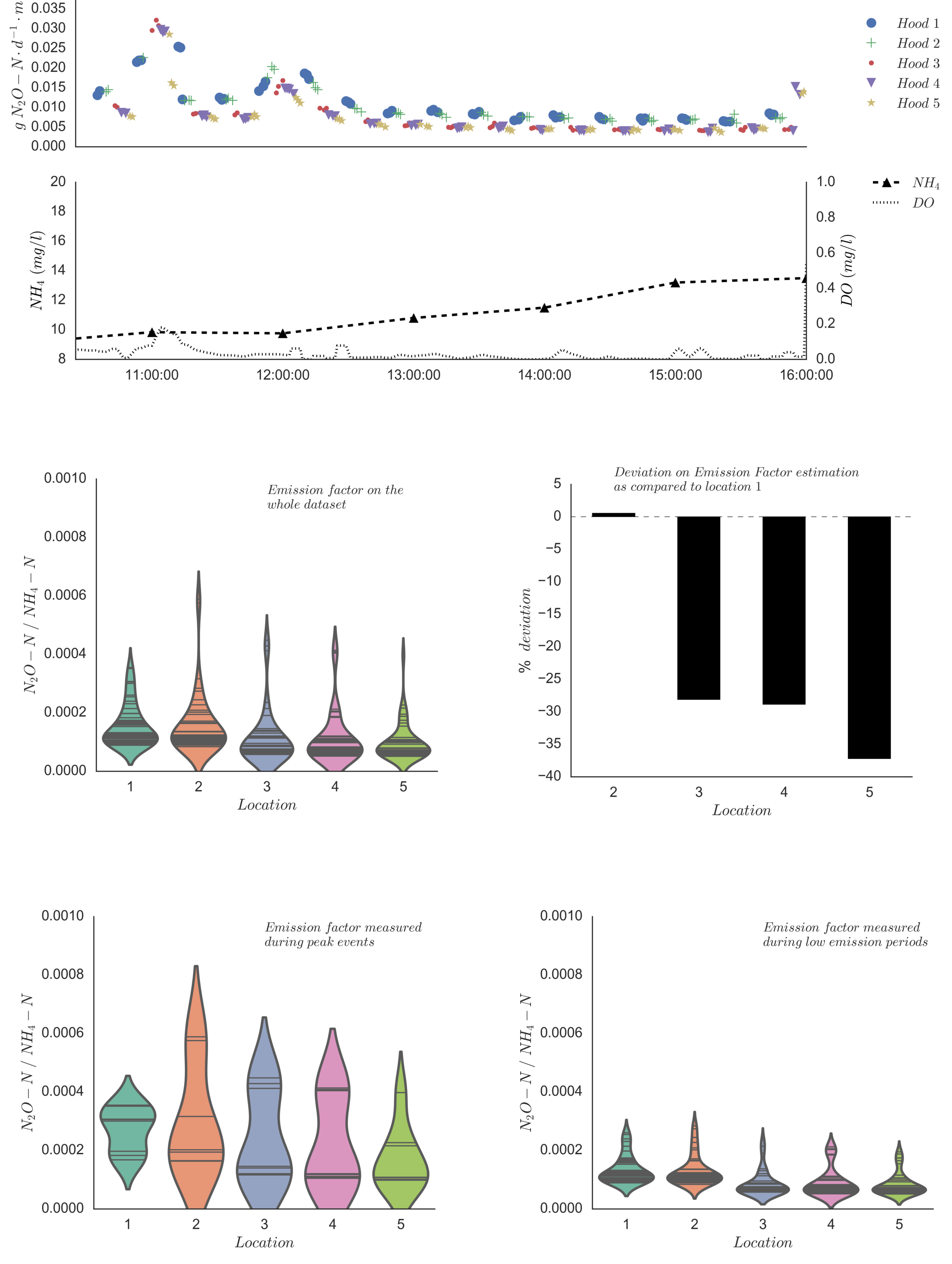

\section{Full-scale measurements}

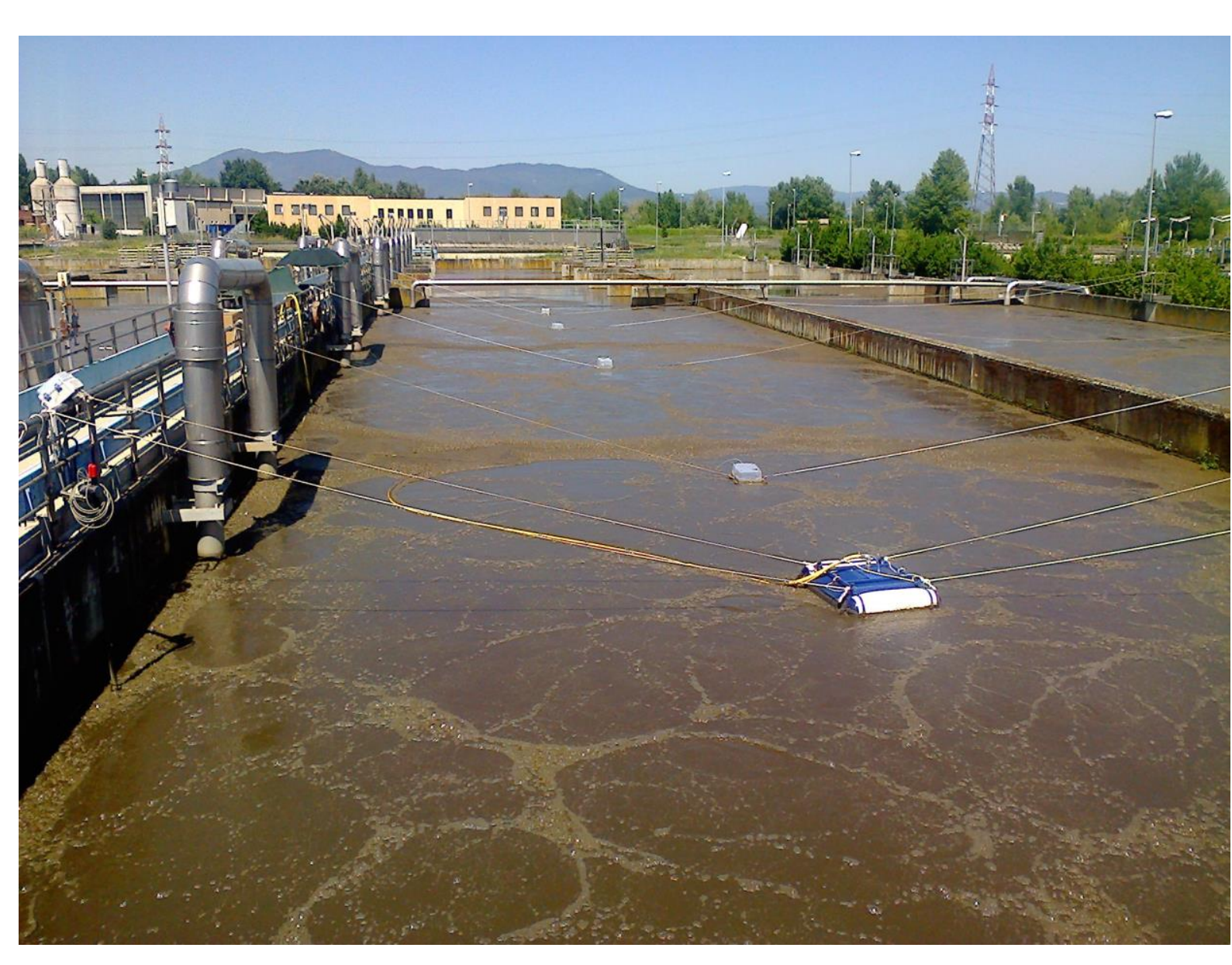

$\mathrm{N}_{2} \mathrm{O}$ was measured with an IR analyzer using 5 hoods in parallel to understand spatial and temporal dynamics and their effect on the emission factor.

Aeration efficiency was measured using an off-gas analyzer and a floating hood positioned to cover $3.4 \%$ of the area of the tank

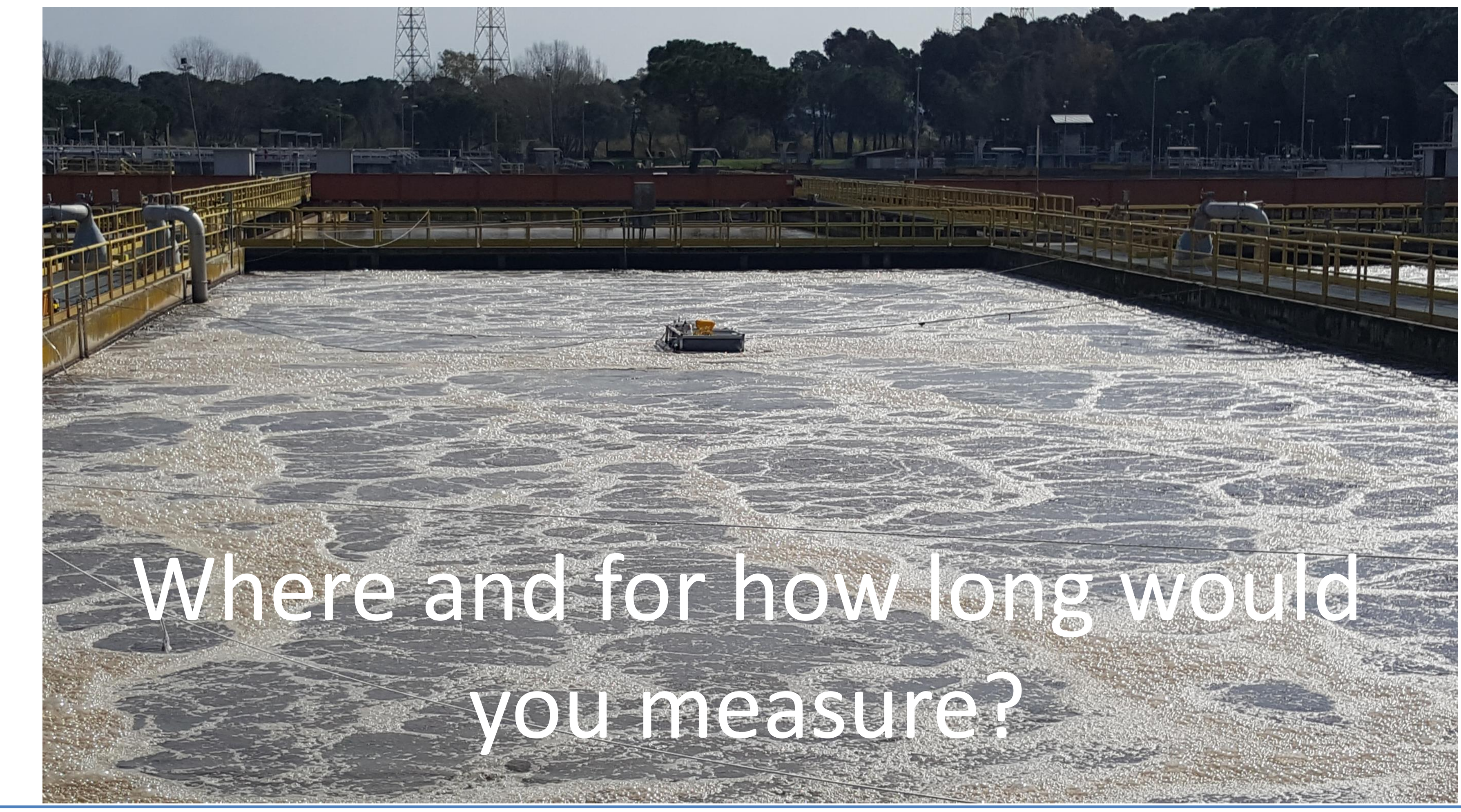

\section{Aeration efficiency}

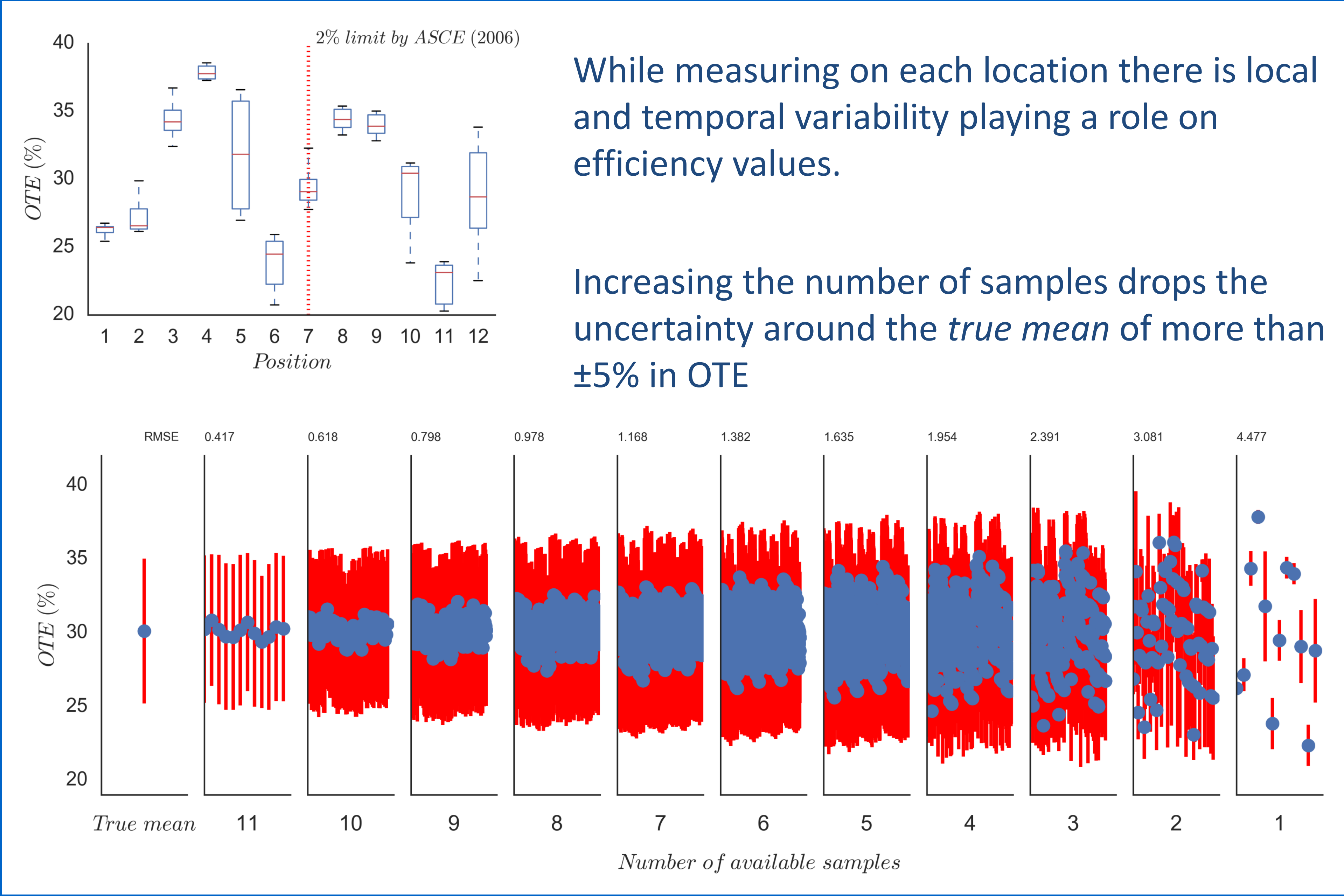

\section{Conclusions}

The measurement strategy plays an important role on $\mathrm{N}_{2} \mathrm{O}$ emission and aeration efficiency assessment. Both the spatial and temporal variability of the plant need to be taken into account.

- Current general guidelines need to be adjusted according to available knowledge.

- Plant-specific and dedicated strategies must be defined for each different plant.

\section{Contact}

Giacomo.Bellandi@dicea.unifi.it

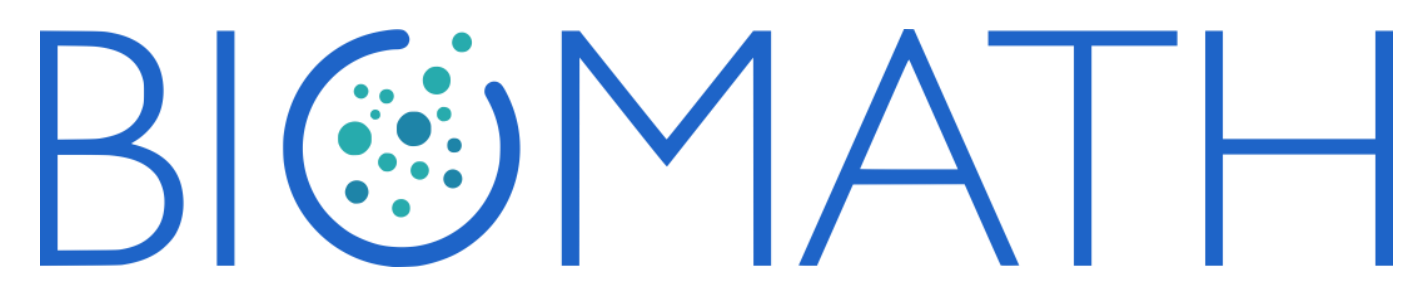

ofo Frontiers International Conference on Wastewater TreatMent 21-24 MAY 2017 PALERMO - ITALY 国

\section{Want a copy?} Scan the QR code and get a pdf

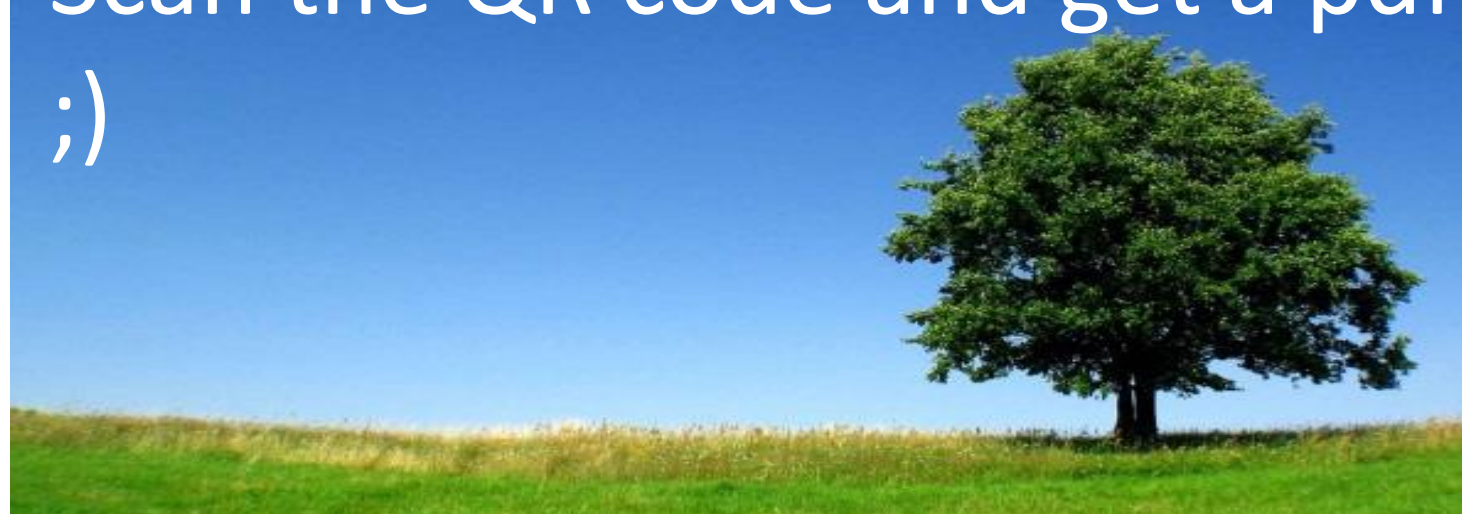

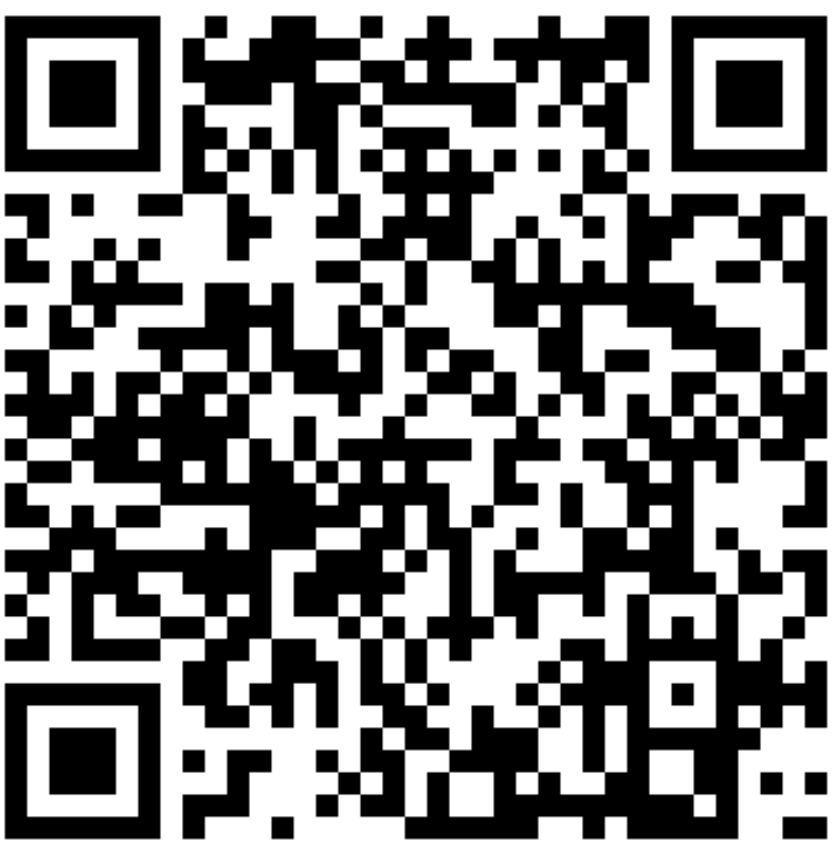

